\title{
Genetic Diversity and Phylogenetic Relationships among Plum Germplasm Resources in China Assessed with Inter-simple Sequence Repeat Markers
}

\author{
Weisheng Liu \\ Institute of Botany, Chinese Academy of Sciences, Beijing, 100093, China, and Liaoning \\ Institute of Pomology, Xiongyue, Liaoning, 115009, China \\ Dongcheng Liu and Aimin Zhang ${ }^{1}$ \\ Institute of Genetic and Developmental Biology, Chinese Academy of Sciences, Beijing, \\ 100101, China \\ Chenjing Feng and Jianmin Yang \\ College of Landscape Architecture and Tourism, Agricultural University of Hebei, \\ Baoding, 071001, China \\ Jaeho Yoon \\ Division of Plant Science, Sunchon National University, Sunchon, 540-742, Korea \\ Shaohua Li ${ }^{1}$
Institute of Botany, Chinese Academy of Sciences, Beijing, 100093, China
}

Additional Index words. Prunus spp., ISSR, DNA polymorphism, similarity, geographic origin, clustering, principal coordinate analysis

\begin{abstract}
Inter-simple sequence repeat (ISSR) markers were used to evaluate genetic similarity and interrelationship among 104 plum (Prunus L. spp.) and related accessions from the Chinese National Germplasm Repository for Plums and Apricots and the Tianshan Germplasm Repository for Wild Fruit Resources, including six plum species (Prunus salicina Lindl., Prunus simonii Carr., Prunus ussuriensis Kov. et Kost., Prunus domestica L., Prunus cerasifera Ehrh., and Prunus spinosa L.), two related species [apricot (Prunus armeniaca L.) and nanking cherry (Prunus tomentosa Thunb.)], eight putative hybrids between plum and apricot (plumcot), and six accessions of wild European plum (P. domestica). Out of the 42 ISSR primers, 12 were selected, which generated 103 markers in total, 99 of which were polymorphic. Possible accession-specific ISSR bands or patterns were also found. Some possible synonyms or homonyms were clarified or discussed, and closely related accessions such as bud mutants were discriminated. Based on the unweighted pair group method with arithmetic mean (UPGMA) analysis and principal coordinate analysis (PCoA) using the Jaccard coefficient, two different dendrograms were constructed-one including accessions grouped by species and one with all 104 accessions—and a two-dimensional plot was obtained. Three groups were formed in both dendrograms and PCoA plot: Group I including apricot ('Yinxiangbai') and plumcot types; Group II containing Asia-originated diploid species [e.g., P. cerasifera, P. ussuriensis, P. tomentosa, and Chinese plum-types (i.e., $P$. salicina and its hybrids)]; and Group III involving European-origin polyploid species (e.g., $P$. spinosa and $P$. domestica) and recently found wild European plum accessions in China. The dendrogram with accessions grouped by species implied that 1) plumcot types had closer relatedness with apricot than with plum; 2) $P$. simonii should be a variant of $P$. salicina while $P$. ussuriensis an independent species; 3$) P$. domestica was more closely related to $P$. spinosa than to $P$. cerasifera. Two accessions of European plum ('89-7-3' and 'Wanhei') were clustered into outgroups in the dendrogram with all 104 accessions, which could been grouped within Group III in the PCoA plot. The distribution of both European plum and Chinese plum-types across respective groups did not reflect the geographic origins. The present study also further confirmed that the wild plants found in Xinjiang of China were $P$. domestica.
\end{abstract}

\footnotetext{
Received for publication 6 Nov. 2006. Accepted for publication 27 Apr. 2007. This study was made possible by funding from the Knowledge Innovation Programme (KIP) of Chinese Academy of Sciences. This experiment complies with the current laws of P.R. China.

We are grateful to Dr. B. Topp (Queensland Horticulture Institute of Australia), Prof. David H. Byrne (Texas A\&M University), and Prof. W. Loescher (Michigan State University) for having reviewed our manuscript.

${ }^{1}$ Corresponding authors. E-mail: shhli@ibcas.ac.cn and amzhang@genetics. ac.cn.
}

Plums are among the most important stone fruit crop in the world (Bhutani and Joshi, 1995). The largest producer is China, with an annual production of 4,635,600 metric tons in 2005 [Food and Agriculture Organization of the United Nations (FAO), 2006], accounting for $47 \%$ of the world production.

Plums belong to the genus Prunus. There are two important plum types: European plum (Prunus domestica, $2 \mathrm{n}=6 \mathrm{x}=48$ ) and Chinese plum-types, including both pure Chinese plum 
(Prunus salicina, $2 \mathrm{n}=2 \mathrm{x}=16$ ) and its hybrids with other diploid plum species, such as Prunus simonii, Prunus cerasifera, Prunus americana, and others (Bhutani and Joshi, 1995). European plum is used for both drying and fresh markets, while Chinese plum-types are used mainly for fresh market.

European plum and Chinese plum-type cultivars, particularly the improved cultivars grown in California, have a narrow base of genetic diversity, making them not only limited in adaptability but also more susceptible to disease and insect attack (Ramming and Cociu, 1990). For example, eight of the top 10 plum cultivars in commercial production in California trace back to just five parents, all released by Luther Burbank (Okie and Weinberger, 1996).

Although plum production in China has increased rapidly in the past decade, much of the production is still based on selected old or local cultivars, such as 'Qiuli' and 'Wanhong' in northern China and 'Furongli' and 'Naili' in southern China, which have good flavor and adaptability but lack firm flesh and attractive appearance (Liu, 2004). Some improved plum cultivars, such as 'Friar', 'Blackamber', and 'Casselman', have been introduced from the United States into China recently, but most of them have insipid flavor, weak coldhardiness, and are susceptible to bacterial spot [Xanthomonas arboricola pv. pruni (Smith) Dye], the main plum disease in China (Liu, 1996).

Genetic variability is the prerequisite for any plant breeding program (Khush, 2002). Using diverse plum resources to broaden the genetic base of worldwide plum cultivars and improving local plum cultivars for development of plum industry in China are important objectives for plum breeders.

As an origin center of Chinese plum, China has rich plum germplasm resources. According to Zhang (1990), there are eight species, five botanical varieties, and $\approx 800$ local cultivars distributed from Yi'an in Heilongjiang Province (lat. $47^{\circ} 50^{\prime} \mathrm{N}$ ) to the middle parts of the Leizhou Peninsula (around lat. $21^{\circ} \mathrm{N}$ ) in the southernmost parts of Guangdong Province. The Chinese National Germplasm Repository for Plums and Apricots was established at Xiongyue in Liaoning Province in 1986. It presently contains 600 accessions of local and improved cultivars and has been under an active collection program. The diversity of plum germplasm in China is attributed to natural and artificial selection for adaptation and other characteristics over a long period of time and in a wide array of ecological conditions.

Prunus domestica has been cultivated in Europe for at least 2000 years, but no distinctly wild form is known (Westwood, 1993). The genetic origin of European plum remains a controversial issue. Crane and Lawrence (1952) suggested that $P$. domestica, a hexaploid, originated as a hybrid between Prunus cerasifera, a diploid, and Prunus spinosa, a tetraploid, via either chromosome doubling of the hybrid triploid or as a product of unreduced gametes from both parents. Zohary (1992) proposed that $P$. domestica was an autopolyploid derived from $P$. cerasifera rather than an allopolyploid. Eryomine (1991) even suggested that many other species, including Prunus microcarpa C.A. Mey., Prunus salicina, Prunus armeniaca, and Prunus persica (L.) Batsch, could be included.

Recent surveys from Xinjiang in northwestern China found apparently native stands of $P$. domestica in wild forests along the Ili River. Neither of the presumed parental species was found nearby (Lin and Shi, 1990). This finding may shed light on the genetic origin of European plum after in-depth investigation on wild populations. The wild European plum may also be helpful to broaden the genetic base of cultivated plum cultivars.
Before these cultivated or wild resources can be exploited efficiently, they must be systematically evaluated for genetic diversity assessment. We had evaluated the genetic diversity of Chinese plum resources on the basis of morphological traits and isozyme polymorphisms (Zhang and Zhou, 1998); however, morphological traits were highly influenced by the environment, so estimates of genetic diversity were not precise and isozymes were few in number and hence were not very efficient for characterization of the genetic diversity in the germplasm (Khush, 2002).

The advent of DNA molecular markers has ushered in a new epoch in the efficient characterization and identification of germplasm resources. Restriction fragment length polymorphism (RFLP) analysis was the first molecular technique to be used for this purpose. However, RFLPs have the disadvantages of being time-consuming and labor-intensive, and they often involve the use of radioactive materials (Fang et al., 1997). Moreover, this procedure also requires relatively large quantities of sample DNA. Randomly amplified polymorphic DNA (RAPD) analysis is a simple, quick, and convenient procedure requiring much smaller quantities of template DNA, but the reproducibility of this approach has often been questioned (Jones et al., 1997; Virk et al., 2000). Microsatellites or simple sequence repeat (SSR) markers with tandem repeats of a basic motif of $<6$ bp are the most polymorphic and hence are highly useful markers; however, their development is laborious and expensive (Ammiraju et al., 2001).

Recently, inter-simple sequence repeat (ISSR) markers (Gupta et al., 1994; Zietkiewicz et al., 1994) have emerged as an alternative system with the reliability and advantages of microsatellites (SSR). This approach had been used in several fruit crops, such as blueberry [Vaccinium L. (Levi and Rowland, 1997)], strawberry [Fragaria L. (Cekic et al., 2001)], citrus [Citrus L. (Sankar and Moore, 2001)], grape [Vitis vinifera L. (Moreno et al., 1998)], trifoliate orange [Poncirus trifoliata (L.) Raf. (Fang et al., 1997)], and cashew [Anacardium occidentale L. (Archak et al., 2003)] for the purposes of cultivar identification, germplasm collection or natural population diversity evaluation, phylogenetic relationship analysis, genetic linkage mapping, and marker assistant selection. For plums, phenetic characterization of 24 Chinese plum-types and four European plum cultivars has been reported (Goulao et al., 2001), but no studies on the diversity of the Chinese plum collection have been conducted.

To draw information on genetic variation of plum germplasm resources in China and advance their collection, management, and utilization, a subset of plum collection from two germplasm repositories in China was characterized with ISSR markers in the present study, specifically aiming to 1) identify duplicated or mislabeled accessions, 2) evaluate diversity to facilitate its use in breeding and in developing a collection strategy, and 3) analyze the genetic relationship of plum species, focusing on the origin of European plum.

\section{Materials and Methods}

Plant material. One hundred four (104) accessions were tested, which represented six plum species ( $P$. salicina, $P$. simonii, $P$. ussuriensis, $P$. domestica, $P$. cerasifera, and $P$. spinosa), two related species ( $P$. armeniaca and $P$. tomentosa), eight plumcots, and six accessions of wild European plum (Table 1); and all were collected from the Chinese National 
Table 1. Accessions of Prunus assayed with ISSR markers in present study.

\begin{tabular}{|c|c|c|c|c|}
\hline Accession no. & Planting no. ${ }^{\mathrm{z}}$ & Accession name & Species $^{y}$ & Origin \\
\hline 1 & A1-1 & Xingmeili & Plumcot & China \\
\hline 2 & A $1-2$ & Retsudo Burubetsuto & Plumcot & Japan \\
\hline 3 & A1-3 & Zhuanzihong & Plumcot & China \\
\hline 5 & A2-6 & Yingtaoli & P. cerasifera & China \\
\hline 6 & A2-7 & Hongyeli & P. cerasifera & China \\
\hline 7 & A2-11 & Huangniuxinli & P. simonii & China \\
\hline 9 & A2-13 & Bianyan & P. simonii & China \\
\hline 10 & A2-14 & Xiangbianli & P. simonii & China \\
\hline 11 & A2-15 & Xiangbianli & P. simonii & China \\
\hline 12 & A3-15 & Bingtangli & P. domestica & Unknown \\
\hline 13 & A3-14 & Bingtangli & P. domestica & Unknown \\
\hline 14 & A4-12 & Angeleno & P. salicina hybrid & United States \\
\hline 19 & A4-8 & $89-7-6$ & P. domestica & United States \\
\hline 20 & A4-7 & Dameigui & P. domestica & Unknown \\
\hline 21 & A3-6 & $\mathrm{Li} \# 8$ & P. domestica & Italy \\
\hline 22 & TGRWF & Xinjiang \#2 & Wild $P$. domestica & China \\
\hline 23 & A4-5 & Wanhei & P. domestica & Unknown \\
\hline 24 & A3-5 & Tianli & P. domestica & Unknown \\
\hline 25 & A4-4 & Ganli & P. domestica & Unknown \\
\hline 26 & A4-3 & Richard Early & P. domestica & Italy \\
\hline 27 & A3-3 & Ainula & P. domestica & China \\
\hline 28 & A4-2 & Mt. Royal & P. domestica & United States \\
\hline 29 & TGRWF & Xinjiang \#3 & Wild $P$. domestica & China \\
\hline 37 & A5-4 & Friar & P. salicina hybrid & United States \\
\hline 38 & A6-4 & Suili \#3 & P. salicina & China \\
\hline 39 & A5-5 & Akihime & P. salicina & Japan \\
\hline 40 & A6-5 & Dahainiuxinli & P. salicina & China \\
\hline 41 & A5-6 & Product & P. salicina & United States \\
\hline 42 & A6-6 & Cuoli & P. salicina & China \\
\hline 43 & A5-7 & Pingguoli & P. salicina & China \\
\hline 44 & A6-7 & Lushanli & P. salicina & China \\
\hline 45 & A5-8 & Kuandiandali & P. salicina & China \\
\hline 46 & A5-9 & Qiuli & P. salicina & China \\
\hline 47 & A6-9 & Tongpannai & P. salicina & China \\
\hline 48 & A5-10 & Lihe \#1 & P. salicina & China \\
\hline 49 & A6-10 & Wanhong & P. salicina & China \\
\hline 50 & A5-11 & Lihe \#2 & P. salicina & China \\
\hline 51 & A6-11 & Huanai & P. salicina & China \\
\hline 52 & A5-12 & Lihe \#4 & P. salicina & China \\
\hline 53 & A6-12 & Ruth Grestetter & P. domestica & Germany \\
\hline 54 & A5-13 & Ozark Premier & P. salicina hybrid & United States \\
\hline 55 & A6-13 & Xiangyanghong & P. salicina & China \\
\hline 56 & A6-14 & Kaiyuanli & P. salicina & China \\
\hline 57 & A6-15 & Yanjili & P. salicina & China \\
\hline 58 & A5-15 & Au-Producer & P. salicina hybrid & United States \\
\hline
\end{tabular}


Table 1. Continued.

\begin{tabular}{|c|c|c|c|c|}
\hline Accession no. & Planting no. ${ }^{\mathrm{z}}$ & Accession name & Species $^{\mathrm{y}}$ & Origin \\
\hline 59 & A8-15 & Tiankanmali & P. salicina & China \\
\hline 60 & A7-15 & $2-214$ & P. domestica & United States \\
\hline 61 & A7-14 & Batangli & P. salicina & China \\
\hline 63 & A7-13 & $2-213$ & P. salicina & United States \\
\hline 64 & A7-12 & Sanhuali & P. salicina & China \\
\hline 67 & A8-9 & Zhushali & P. salicina & China \\
\hline 68 & A7-8 & Suilinglimei & P. salicina & China \\
\hline 69 & A8-8 & Qingpihongxin & P. salicina & China \\
\hline 70 & A8-7 & Santa Rosa & P. salicina hybrid & United States \\
\hline 71 & A8-6 & Ozark Premier & P. salicina hybrid & United States \\
\hline 72 & A8-5 & Au-cherry & P. salicina hybrid & United States \\
\hline 76 & A7-2 & Guali & P. salicina & China \\
\hline 77 & A9-1 & Gecko & P. salicina & Japan \\
\hline 78 & A9-2 & Hongrouli & P. salicina & China \\
\hline 79 & A9-3 & Jiaqingzi & P. salicina & China \\
\hline 80 & A9-4 & Ziyu & P. salicina & China \\
\hline 81 & A9-5 & Xiangjiaoli & P. salicina & China \\
\hline 82 & A10-6 & Yuhuangli & P. salicina & China \\
\hline 83 & B7-2 & Jinshuai & P. salicina & China \\
\hline 84 & B7-1 & Changli \#15 & P. salicina & China \\
\hline 85 & A14-7 & Dongbeimeili & P. salicina & China \\
\hline 86 & B5-4 & Fortune & P. salicina hybrid & United States \\
\hline 87 & A15-14 & Beauty & P. salicina & United States \\
\hline 95 & A16-8 & Hollywood & P. salicina hybrid & United States \\
\hline 96 & E14-2 & Maoyingtao & P. tomentosa & China \\
\hline 97 & A1-5 & Xingmei & Plumcot & China \\
\hline 98 & A1-6 & Xingli & Plumcot & United States \\
\hline 99 & A2-2 & Heicili & P. spinosa & China \\
\hline 100 & A2-3 & Xiangjiaoli & P. ussuriensis & China \\
\hline 101 & A3-13 & Stanley & P. domestica & United States \\
\hline 102 & A3-11 & Danding & P. domestica & Unknown \\
\hline 103 & A5-14 & Naili & P. salicina & China \\
\hline 104 & A12-2 & Oishi Nakade & P. salicina & Japan \\
\hline
\end{tabular}

${ }^{z}$ TGRWF refers to samples collected from the Tiansan Germplasm Repository for Wild Fruit Resources, located in Xinyuan County, Xinjiang Province, China.

${ }^{y}$ Plumcot $=$ natural or artificial hybrid between plum and apricot $(P$. armeniaca $) ; P$. salicina hybrid $=$ hybrid between $P$. salicina and other diploid plum species.

Germplasm Repository for Plums and Apricots located in Xiongyue, Liaoning Province, China, except for six accessions of wild European plum, which were sampled from the Tianshan Germplasm Repository for Wild Fruit Resources located in Xinyuan, Xinjiang Province, China.

DNA EXTRACTION. Samples were taken from three plants of each accession. DNA extraction was performed using the CTAB method (Doyle and Doyle, 1990) with modification.
Briefly, $\approx 0.1 \mathrm{~g}$ of frozen leaves was put into a $1.5-\mathrm{mL}$ Eppendorf tube and ground to a fine powder in liquid nitrogen with a specially designed grinder. The powder was added to 650 $\mu \mathrm{L}$ of extraction buffer ( $2 \%$ CTAB, $1.4 \mathrm{~m} \mathrm{NaCl}, 100$ mм Tris$\mathrm{HCl}, 20 \mathrm{~mm}$ EDTA, 2\% BME, 1\% PVP) and incubated at $65^{\circ} \mathrm{C}$ for 30-60 min. After this mixture had been placed in an ice-bath for $5 \mathrm{~min}$. DNA was extracted once with one volume of chloroform/isoamyl alcohol (24:1, v/v). The DNA suspension 
was mixed gently and centrifuged at $15,300 g_{n}\left(4^{\circ} \mathrm{C}\right)$ for $15 \mathrm{~min}$. The top aqueous phase was collected into a new tube, and $2 \mu \mathrm{L}$ of RNase $\left(10 \mathrm{mg} \cdot \mathrm{mL}^{-1}\right)$ was added, mixed, and then incubated at $37{ }^{\circ} \mathrm{C}$ for $30-60 \mathrm{~min}$. DNA was extracted once more with one volume of the chloroform/isoamyl mixture, the top aqueous phase was collected again, and the DNA was precipitated with two volumes of cold ethanol. The DNA pellet was washed three times with $70 \%$ ethanol and dissolved in $100 \mu \mathrm{L}$ of sterile water after the ethanol evaporated completely. DNA quality was checked on a $1 \%$ agarose gel, and the concentration was determined by spectrophotometry at $260 \mathrm{~nm}$. A portion of the DNA was diluted to $20 \mathrm{ng} \cdot \mu \mathrm{L}^{-1}$ for use, and the stock and diluted portions were stored at -20 and $4{ }^{\circ} \mathrm{C}$, respectively.

PCR PROCEDURE. PCR reaction mixtures had a total volume of $20 \mu \mathrm{L}$ containing $60 \mathrm{ng}$ of DNA template, $0.25 \mu \mathrm{M}$ primer, $0.2 \mathrm{~mm}$ dNTPs, 0.25 unit of Taq DNA polymerase, $3.0 \mathrm{~mm}$ $\mathrm{MgCI}_{2}, 2 \mu \mathrm{L} \mathrm{10 \times}$ buffer [20 mм $\mathrm{MgSO}_{4}, 100 \mathrm{~mm} \mathrm{KCl}, 80 \mathrm{~mm}$ $\left(\mathrm{NH}_{4}\right)_{2} \mathrm{SO}_{4}, 100 \mathrm{~mm}$ Tris-HCl, 0.5\% NP-40, $\mathrm{pH}$ 9.0]. Reaction mixtures were overlaid with $50 \mu \mathrm{L}$ of mineral oil.

Amplifications were performed on a DNA Thermal Cycler 9700 (PerkinElmer, Wellesley, MA) with the following temperature profile: a pre-denaturation step of $5 \mathrm{~min}$ at $94{ }^{\circ} \mathrm{C}$ followed by 40 cycles of denaturation, $45 \mathrm{~s}$ at $94{ }^{\circ} \mathrm{C}$; annealing, $1 \mathrm{~min}$ at $52{ }^{\circ} \mathrm{C}$; extension, $90 \mathrm{~s}$ at $72{ }^{\circ} \mathrm{C}$. A final extension was allowed for $5 \mathrm{~min}$ at $72{ }^{\circ} \mathrm{C}$.

Amplified products were separated by electrophoresis on $2 \%$ agarose gel in $1 \times$ TAE buffer under a voltage of $40 \mathrm{~V} \cdot \mathrm{cm}^{-1}$ for $\approx 1.5 \mathrm{~h}$ and visualized with staining by ethidium bromide, and then ultraviolet-transilluminated gels were photographed.

DAta anAlysis. Amplification fragments were scored as present (1) or absent (0). Faintly stained bands were not included in the analysis. Each reaction was repeated twice, hence only reproducible products were included in the study. Based on the number of shared amplification products, data for all 12 primers were assembled into a data matrix. The UPGMA cluster analysis and PCoA were performed using the NTSYSpc version 2.1 software (Rohlf, 2000) based on the Jaccard coefficient of similarity, and two dendrograms, one with accessions grouped by species and one including all 104 accessions, and a scatter plot were obtained. Mantel tests (Mantel, 1967) were carried out to calculate goodness-of-fit between the cluster analyses and original matrices.

\section{Results}

In a pilot experiment, the effects of various levels of magnesium concentrations $(1.0,1.5,2.0,2.5$, and $3.0 \mathrm{~mm}$ ), template DNA concentrations $(10,20,40,60$, and $80 \mathrm{ng})$, dNTP concentrations $(0.1,0.15,0.2,0.25$, and $0.3 \mathrm{~mm})$, Taq polymerase contents $(0.25,0.5,1.0,1.5$, and $2.0 \mathrm{U})$, primer concentrations $(0.1,0.15,2.0,2.5$, and $3.0 \mathrm{~mm})$, and annealing temperatures $(49,49.3,50,50.8,52.1,53.7,55.6,57.1,58.3$, $59.2,59.8$, and $60{ }^{\circ} \mathrm{C}$ ) on amplification results were examined using the DNA samples of 'Xingmeili' (accession no. 1) and 'Stanley' (101) and optimized conditions, as described in Materials and Methods, were obtained. Under the optimized reaction system, 42 ISSR primers from University of British Columbia, Canada, were tested, among which 12 primers (Table 2) were selected for their reproducible and clear band patterns.

A total of 103 bands were scored with an average band number of 8.6 per primer across 104 accessions assayed. Among the 103 bands, 99 bands (96.1\%) were polymorphic,
Table 2. ISSR primers used for the genetic diversity evaluation of 104 plum and related accessions and their amplification performance.

\begin{tabular}{llccc}
\hline $\begin{array}{l}\text { Primer } \\
\text { code }\end{array}$ & Sequence $^{\mathrm{z}}$ & $\begin{array}{c}\text { Total no. } \\
\text { of bands }\end{array}$ & $\begin{array}{c}\text { No. of } \\
\text { polymorphic } \\
\text { bands }\end{array}$ & $\begin{array}{c}\text { Percent of } \\
\text { polymorphic } \\
\text { bands (\%) }\end{array}$ \\
\hline 810 & $(\mathrm{GA})_{8} \mathrm{~T}$ & 8 & 8 & 100 \\
818 & $(\mathrm{CA})_{8} \mathrm{G}$ & 9 & 9 & 100 \\
825 & $(\mathrm{AG})_{8} \mathrm{~T}$ & 7 & 5 & 71.4 \\
827 & $(\mathrm{AC})_{8} \mathrm{G}$ & 4 & 4 & 100 \\
841 & $(\mathrm{GA})_{8} \mathrm{YC}$ & 9 & 9 & 100 \\
845 & $(\mathrm{CT})_{8} \mathrm{RG}$ & 10 & 10 & 100 \\
848 & $(\mathrm{CA})_{8} \mathrm{RG}$ & 6 & 5 & 83.3 \\
853 & $(\mathrm{TC})_{8} \mathrm{RT}$ & 10 & 10 & 100 \\
855 & $(\mathrm{AC})_{8} \mathrm{YT}$ & 6 & 5 & 83.3 \\
857 & $(\mathrm{AC})_{8} \mathrm{YG}$ & 12 & 12 & 100 \\
868 & $(\mathrm{GAA})_{5}$ & 9 & 9 & 100 \\
880 & $(\mathrm{GGAGA})_{3}$ & 13 & 13 & 100 \\
Total & & 103 & 99 & 96.1 \\
\hline
\end{tabular}

${ }^{\mathrm{z}} \mathrm{Y}=\mathrm{C}$ or $\mathrm{G} ; \mathrm{R}=\mathrm{A}$ or $\mathrm{T}$.

and only four bands were monomorphic. These results indicated a high level of diversity in the 104 accessions under investigation.

Twenty-six accession-specific band patterns were identified (Table 3). In total, seven accession-specific band patterns were obtained for accession 23 ('Wanhei', a European cultivar with unknown name), three for accession 89 ('Yingxiangbai', a white-flesh local apricot cultivar), three for accession $96(P$. tomentosa, a common rootstock for plum in northern China), two for accessions 6 ('Hongyeli', red-leaf plum, a variant of $P$. cerasifera) and 101 ('Stanley', a U.S. hybrid-derived European plum cultivar), and one for accessions 2, 13, 16, 60, 99, 100, and 102 , respectively.

There were two possible accession-specific bands among the total 103 bands obtained. One was Primer 853-450 bp for all cultivated European plum and another Primer 827-400 bp for '2-214' (accession no. 60).

Genetic similarities between accessions were estimated using the Jaccard coefficient, and the similarity coefficient matrix was established (data not shown). The similarity values varied from 0.19 for '89-7-3' (15) versus 'Limixing' (91) to

Table 3. ISSR primers generating unique band patterns to some Prunus accessions tested.

\begin{tabular}{ll}
\hline Accession name (no.) & $\begin{array}{c}\text { Primers generating } \\
\text { unique band pattern }\end{array}$ \\
\hline Hongyeli (6) & Primers 818,857 \\
Wanhei (23) & Primers $818,845,853$, \\
& $855,857,868,880$ \\
Maoyingtao (96) & Primers 818, 853, 855 \\
Bingtangli (13) & Primer 845 \\
89-7-3 (15) & Primers 845,880 \\
Heicili (99) & Primer 848 \\
Stanley (101) & Primers 848,857 \\
Retsudo burubetsuto (2) & Primer 853 \\
Yinxiangbai (89) & Primers $853,855,868$ \\
Xiangjiaoli (100) & Primer 855 \\
2-214 (60) & Primer 857 \\
Danding (102) & Primer 857 \\
$89-7-4$ (16) & Primer 880 \\
\hline
\end{tabular}


Table 4. Average Jaccard coefficients of 10 Prunus species or groups within and between them based on ISSR data

\begin{tabular}{|c|c|c|c|c|c|c|c|c|c|c|}
\hline Species $^{z}$ & 0 & $\bigcirc$ & $\bar{t}$ & $\diamond$ & 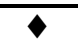 & $\square$ & $\square$ & $\Delta$ & $\triangle$ & $\%$ \\
\hline P. salicina and its hybrids (59) & $0.74^{\mathrm{y}}$ & & & & & & & & & \\
\hline P. simonii (5) & 0.68 & 0.91 & & & & & & & & \\
\hline it P. ussuriensis (1) & 0.60 & 0.54 & 1 & & & & & & & \\
\hline P. spinosa $(1)$ & 0.47 & 0.43 & 0.56 & 0.42 & 1 & & & & & \\
\hline D. domestica (20) & 0.39 & 0.41 & 0.41 & 0.46 & 0.53 & 0.67 & & & & \\
\hline$\square$ Wild P. domestica (6) & 0.41 & 0.45 & 0.48 & 0.47 & 0.55 & 0.56 & 0.91 & & & \\
\hline$\triangle$ Plumcot $(8)$ & 0.51 & 0.48 & 0.44 & 0.43 & 0.41 & 0.41 & 0.42 & 0.55 & 0.72 & \\
\hline$※$ P. tomentosa $(1)$ & 0.50 & 0.49 & 0.44 & 0.43 & 0.44 & 0.39 & 0.41 & 0.37 & 0.42 & 1 \\
\hline
\end{tabular}

${ }^{\mathrm{z}}$ Numbers in parentheses indicate the numbers of accessions included; P. salicina include both pure $P$. salicina and hybrids between $P$. salicina and other diploid plum species.

${ }^{\mathrm{y}}$ Values on the diagonal line are the similarities within species or groups.

1.00 for 'Xiangjiaoli' (8) versus 'Bianyan' (9) and 'Xinjiang \#4' (92) versus 'Xinjiang \#5' (93). Apparently, 'Xiangjiaoli' (8) and 'Bianyan' (9) are duplicated accessions, as are 'Xinjiang \#4' (92) and 'Xinjiang \#5' (93).

'Tianli' (24) versus 'Ganli' (25); 'Jinshuai' (83) versus 'Changli1 \#5' (84); and 'Pingguoli' (43) versus 'Kuandiandali' (45), which were all difficult to discriminate due to their morphological similarity, showed similarity coefficients of $0.97,0.91$, and 0.90 , respectively. 'Tianli' (24) versus 'Ganli' (25) were both introduced European plum cultivars with unknown original names, and their Chinese translated names, "tianli" and "ganli," mean "sweet plum" in Chinese. The similarity based on ISSR data suggested that the two accessions were possible synonyms.

Three accessions $(8,81$, and 100) have the same name, 'Xiangjiaoli', and they belong to three different species, $P$. simonii, . . salicina, and $P$. ussuriensis, respectively. Similarity coefficients between them range from 0.56 for accession 8 versus accession 100 to 0.72 for accession 8 versus accession 81 , correlating with the growth habit differences between the three mentioned accessions: $P$. simonii is upright, $P$. salicina is intermediate, and $P$. ussuriensis is spreading.
The similarity coefficients of four accession pairs with same names, 'Xiangbianli' (10) versus 'Xiangbianli' (11); 'Bingtangli' (12) versus 'Bingtangli' (13); 'Ruth Grestetter' (30) versus 'Ruth Grestetter' (53); and 'Ozark Premier' (54) versus 'Ozark Premier' (71) were $0.75,0.76,0.55$, and 0.80 , respectively, indicating that four pairs were all homonymous pairs incited by mislabeling.

Jaccard coefficients of similarity of 'Lihe \#1' (48), 'Lihe \#2' (50), and 'Lihe \#4' (52) versus 'Qiuli' (46) were 0.96, 0.93, and 0.98 , respectively, and these results supported the suggestion that the first three were probable bud mutants or seedlings of 'Qiuli' (Zhang and Zhou, 1998). The two pairs of improved plum cultivars, 'Oishi wase' (88) versus 'Oishi nakade' (104) and 'Freedom' (35) versus 'Fortune' (86) were sibling lines, but the similarity coefficients between them were only 0.66 and 0.64 , respectively, showing that the similarity coefficients based on ISSR data did not coincide completely with their pedigree information.

The average Jaccard coefficients within and between species or groups (Table 4) indicated that similarities within species were higher than those between species. Genetic variability within $P$. salicina was lower than within $P$. domestica, and either five accessions of $P$. simonii or six accessions of wild European plum presented low genetic variability. The dendrogram using accessions grouped by species (Fig. 1) was constructed with a cophenetic correlation coefficient of 0.85 by Mantel test. The cophenetic correlation coefficient is considered to be a good representation of the data matrix in the dendrogram if it is $\geq 0.8$ (Romesburg, 1990). This dendrogram showed that $P$. simonii was closer to $P$. salicina than was $P$. ussuriensis to $P$. salicina, although both were very similar to $P$. salicina in morphological traits. $P$. domestica was more closely related to $P$. spinosa than to $P$. cerasifera. Hybrids of plum and apricot were more similar to apricot than to plum.

The clustering results including all 104 accessions tested (Fig. 2),

Fig. 1. Dendrogram of 10 Prunus species or groups generated by ISSR data using UPGMA cluster analysis based on the Jaccard coefficient. 


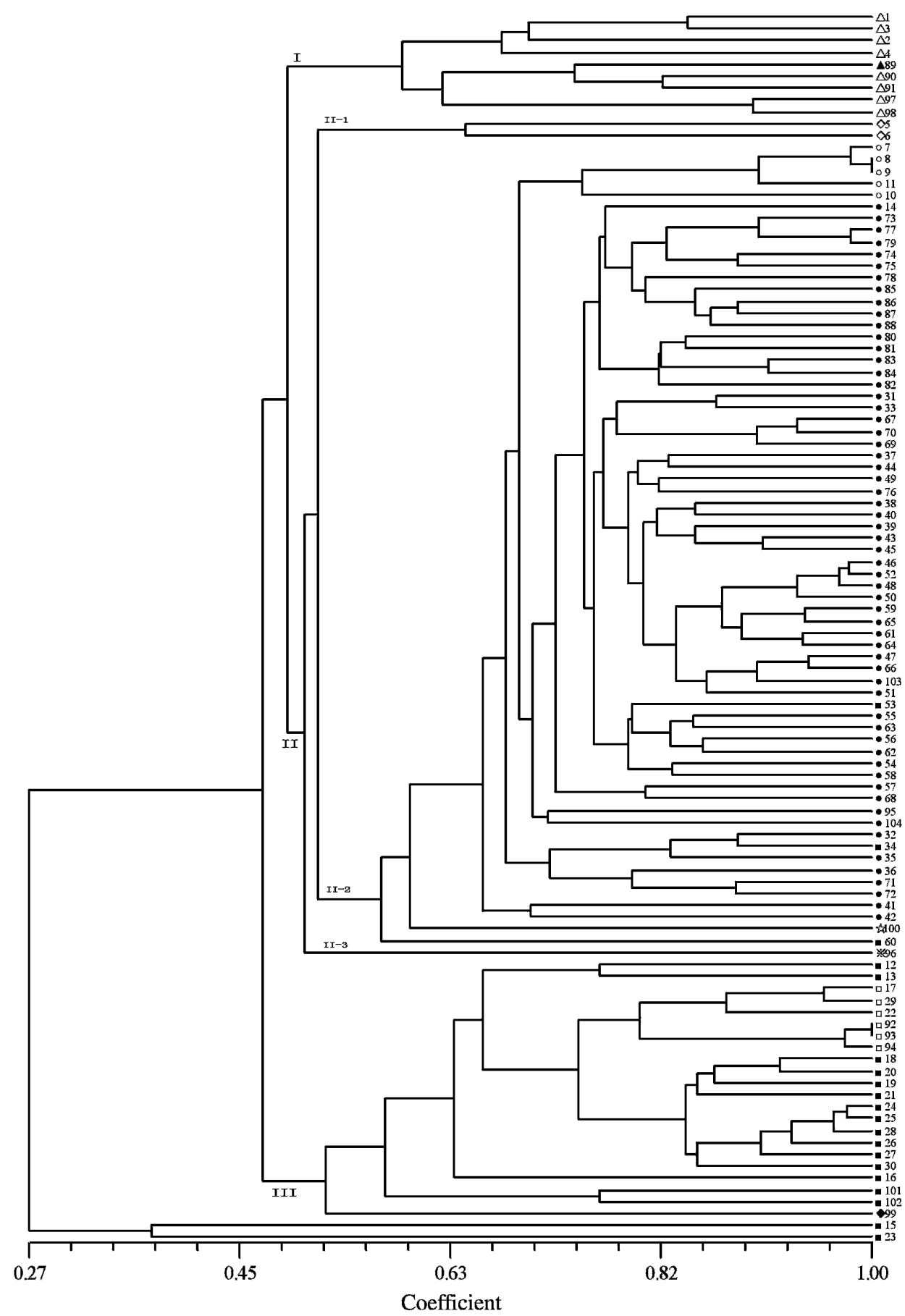

Fig. 2. Dendrogram of 104 plum and related accessions generated by ISSR data using UPGMA cluster analysis based on Jaccard similarity coefficients; $\bigcirc=P$. salicina and its hybrids, $\bigcirc=P$. simonii, $\downarrow=P$. ussuriensis, $\diamond=$ $P$. cerasifera, $\%=P$. tomentosa, $\mathbf{\square}=$ P. domestica, $\square=$ wild $P$. domestica, $\boldsymbol{\nabla}=P$. spinosa, $\boldsymbol{\Delta}=P$. armeniaca, and $\triangle=$ hybrids of plum and apricot ( $P$. armeniaca). The numbers following the symbols are accessions numbers as seen in Table 1. Scale on bottom is the Jaccard coefficient of similarity.

with a cophenetic correlation coefficient of 0.96 by Mantel test, showed that they were divided into three main groups and outgroups. Group I was composed of all eight accessions of plumcot types and one apricot cultivar, Yinxiangbai (89). Group II consisted of all diploid plum accessions and three European cultivar types [i.e., 'President' (34), 'Ruth Grestetter' (53), and '2-214' (60)]. This group has three subgroups, such as cherry plum (containing two accessions of $P$. cerasifera, 5 and
6), Chinese plum-types, and $P$. tomentosa (96). Group III included the tetraploid species ['Heicili' (99)] and all hexaploid European plum, including 6 accessions of wild European plum $(17,22,29,92,93$, and 94), except for three accessions of European plum including accessions 34, 53, and 60 which were mixed into Group II, '89-7-3' (15) and 'Wanhei' (23) which were in the outgroups.

Associations among 104 accessions were also revealed by $\mathrm{PCoA}$ (Fig. 3). In the PCoA plot, similar grouped results were obtained, but two European plum accessions, '897-3' (15) and 'Wanhei' (23), which were divided into outgroups in the clustering result (Fig. 2), could be grouped within Group III, and additional information was revealed (e.g., the plumcots were displaced between apricot and Chinese plumtypes that reflected their phylogenetic relationships), while Eurasian species ( $P$. spinosa and $P$. cerasifera) between European plum and Chinese plum-types that reflected their geographic origins.

\section{Discussion}

ISSR PCR using primers based on dinucleotide, tetranucleotide, or pentanucleotide repeats has now become fashionable among researchers (Zietkiewicz et al., 1994). ISSRs have been used in fruit trees (Archak et al., 2003; Cekic et al., 2001; Fang et al., 1997; Goulao et al., 2001; Levi and Rowland, 1997; Moreno et al., 1998; Sankar and Moore, 2001), but little information is available for evaluation and identification of plum resources using ISSR techniques. Our study further supports ISSR as a reliable, quick, uncomplicated, and cheap method of identification for the large number of accessions held in most collections (Gilbert et al., 1999). This method could be used to eliminate duplicated collections, to discriminate among homonyms or synonyms, to identify closely related accessions, to measure genetic diversity, and to reveal genetic relationships.

Zietkiewicz et al. (1994) noted that primers anchored at the $5^{\prime}$ end displayed more specificity than those anchored at the $3^{\prime}$ end. Fang et al. (1997) also found that in citrus, 5 ' -anchored primers generally had more specificity and thus generated fewer but larger fragments than $3^{\prime}$-anchored ones. However, 10 of 12 


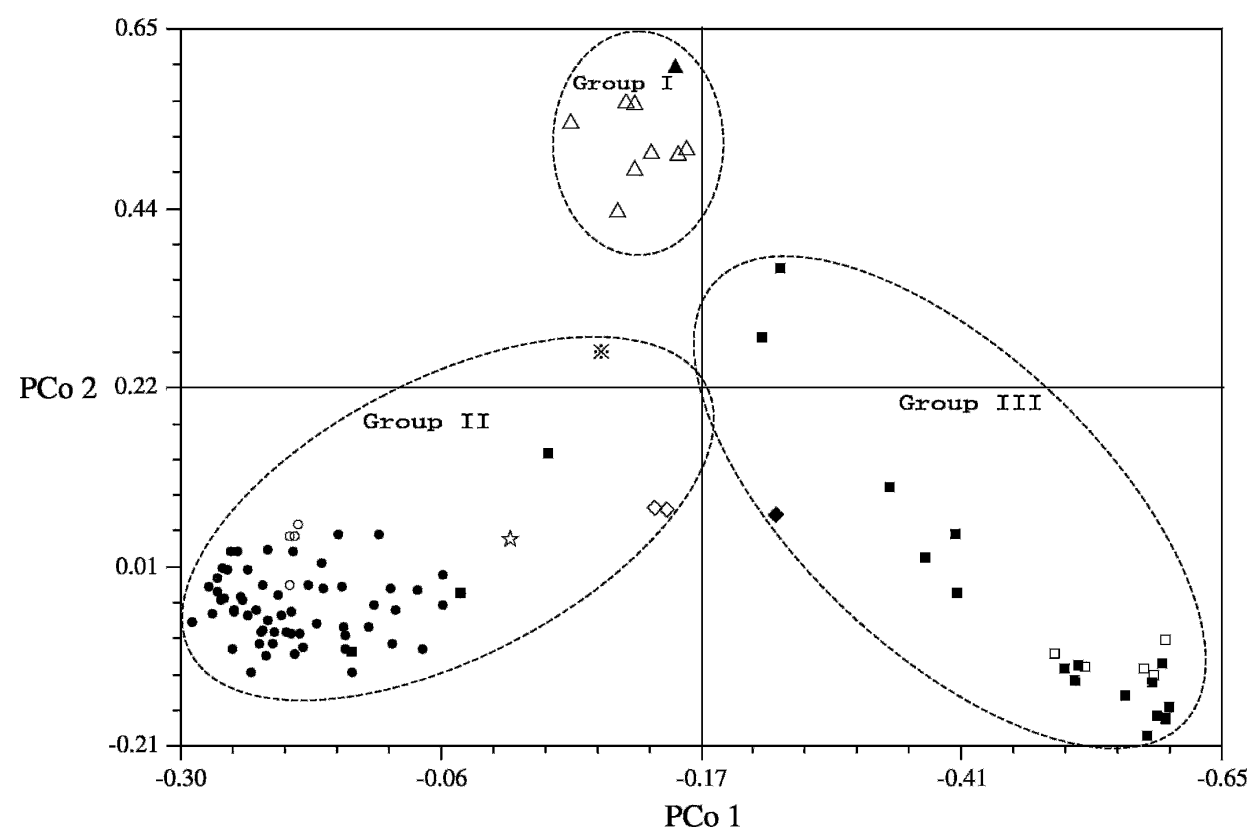

Fig. 3. Two-dimensional plot of 104 plum and related accessions generated by ISSR data using principal coordinate analysis (PCoA) based on the Jaccard coefficients of similarity; $\mathbf{O}=P$. salicina and its hybrids, $\bigcirc=$ $P$. simonii, is $=P$. ussuriensis, $\diamond=P$. cerasifera, $\%=P$. tomentosa, $\mathbf{\square}=P$. domestica, $\square=$ wild $P$. domestica, $\boldsymbol{\nabla}=$ P. spinosa, $\boldsymbol{\Delta}=$ P. armeniaca, and $\triangle=$ hybrids of plum and apricot ( $P$. armeniaca).

primers used in this study were anchored at the $3^{\prime}$ end, and they produced clear patterns too, which is in agreement with the results obtained by Huang and Sun (2000). Wang et al. (1994) reported that $(\mathrm{AT})_{n}$ was the most abundant microsatellite in plant nuclear genomes, but in the present study the primer UBC 880 with the motif of $(\mathrm{GGAGA})_{3}$ generated maximum fragments, suggesting that this pentanucleotide repeat was most frequent among eight motifs tested in plum genomes.

Regarding the effects of primers with same motifs but differently anchored nucleotides, primers UBC 827, 855, and 857 amplified 4, 6, and 12 bands, respectively, and this result supported the observation by Ammiraju et al. (2001) that anchored nucleotides at the $5^{\prime}$ and $3^{\prime}$ ends of the primers play important roles in detecting polymorphism.

Somewhat unexpectedly, the European plum accessions - 'President' (34), 'Ruth Grestetter' (53), and '2-214' (60) - were clustered into same group as diploid accessions, mainly Chinese plum-types. Similar overlaps were observed in the plum dendrogram generated with RAPD characters by Shimada et al. (1999), where three Chinese plum-types, namely 'King', 'Jinsantou', and 'Beauty', were classified into the "European plum group"; these results were considered plausible if these cultivars are interspecific hybrids between Japanese plum ( $P$. salicina) and related species such as $P$. cerasifera or $P$. simonii.

In general, the phenogram showed clustering in good accordance with the classification previously established. One apricot accession (89) was clustered into the same group as all plumcot types, suggesting that seven accessions of hybrids between plum and apricot were possibly more closely related to apricot than to plum. Possible explanations for this were 1) repeated back-crossing plum-apricot hybrids with apricots or 2) favorable selection of the apricot-like descendant from segregating populations as the main objective for the hybridization between plum and apricot in apricot breeding programs as necessary to select a new apricot cultivar with a late flowering time so as to elevate the resistance to spring frost injury for apricot, which has been a serious problem for apricot industry worldwide.

Group II, a diploid species group, included all accessions of $P$. salicina, $P$. cerasifera, $P$. simonii, $P$. ussuriensis, $P$. tomentosa, and $P$. salicina hybrids, among which the first five species were all of Asian origin and the last one was interspecific hybrid between $P$. salicina and other diploid species. Three subgroups were formed in this group, such as the cherry plum subgroup including 'Yingtaoli' (5) and 'Hongyeli' (6), the Chinese plum subgroup including $P$. simonii, $P$. salicina, $P$. ussuriensis, and three accessions of $P$. domestica (accessions 34, 53, and 60), and P. tomentosa subgroup (96).

Chinese plum, $P$. salicina, was native to China, and introduced into Japan no earlier than 1500 AD. Many cultivars were introduced from Japan into California around 1870 and subsequently to Europe. Luther Burbank introduced several Japanese plum cultivars and hybridized them with American native species, resulting in a series of improved plum cultivars, which laid a foundation for fresh market plum production worldwide (Ryugo, 1988). Five plum cultivars from Japan, including 'Akihime' (39), 'Taiyo' (74), 'Gecko' (77), 'Oishi wase' (88), and 'Oishi nakade' (104), were distributed across the Chinese plum subgroup in present dendrogram, indicating that diverse plum resources had been introduced into Japan from China. All the improved Chinese plum hybrids, although most of them derived from interspecific hybridization, were grouped together with pure Chinese plum cultivars possibly due to backcrossing or selection bias, and this result was in agreement with the $P$. salicina-predominating genetic components of improved Chinese plum hybrids (Byrne and Littleton, 1988).

The clustering results did not reflect the geographic origin for both Chinese plum-types in Group II and European plum in Group III (Fig. 2), but the plumcot types were plotted between apricot and Chinese plum and Eurasian species ( $P$. spinosa and $P$. cerasifera) between $P$. domestica and Chinese plum (P. salicina and P. simonii) in the PCoA plot (Fig. 3), which was consistent with their genetic origin and geographic distribution, respectively.

Two European cultivars, '89-7-3' (15) and 'Wanhei' (23), were grouped into distinct outgroups, and another three cultivars [i.e., 'President' (34), 'Ruth Grestetter' (53), and '2214 ' (60)] were intermixed with diploid accessions, suggesting that they may be useful materials to broaden the genetic background of European plum cultivars.

As to the taxonomic placement of $P$. simonii, three opinions exist: the first one is that $P$. simonii is derived from hybridization between apricot and plum (Faust, 1999; Luo et al., 1992; Ruan et al., 2002); the second is that it is thought as an independent species (Qu and Sun, 1990; Wu, 1984; Yu, 1984; 
Zhang and Zhou, 1998); and the last opinion considers $P$. simonii to be a variant of $P$. salicina (Okie and Weinberger, 1996; Yoshida, 1987). Our results support $P$. simonii as a variant of $P$. salicina because all five accessions of $P$. simonii formed a subcluster underneath Group II and were inserted among Chinese plum-types, coinciding with the clustering results with RAPD markers (Boonprakob and Byrne, 2001; Liu et al., 2006).

Prunus salicina was native to Yangtze River basin of China, while $P$. simonii was native to northern China. The present study implied that one or a few individuals of $P$. salicina from Yangtze River basin colonized in a vacant habitat of northern China and a variant was formed as the gene pool of $P$. simonii had low levels of genetic variation (Table 4). In other words, the "founder effect" may have played an important role in the speciation of $P$. simonii.

Although most Chinese taxonomists thought $P$. ussuriensis to be an independent species, Faust (1999) suggested that it was only a minor variation of $P$. salicina. Compared with $P$. simonii, $P$. ussuriensis was distinct from $P$. salicina and its hybrids, so it seems reasonable to consider $P$. ussuriensis as an independent species.

The discovery of putative wild $P$. domestica in a canyon in the Yili region in Xinyuan County, Xinjiang, China (Lin and Shi, 1990), suggested the possibility that European plum may have originated in China. The plants found in Xinjiang, according to their morphological characteristics (Zhang et al., 1998) and chromosome numbers (Lin et al., 1991), belong to $P$. domestica. In present study, six accessions collected from the Tiansan Germplasm Repository for Wild Fruit Resources were clustered into a subcluster underneath Group III, the European plum group, further confirming that they belong to $P$. domestica. High average Jaccard coefficients were presented for six accessions of wild $P$. domestica from six populations from Xinjiang, China (Table 4). This result implied that the cultivated $P$. domestica was brought to Xinjiang and had naturalized there and that Xinjiang was not the origin center of $P$. domestica, as a high level of diversity should exist in the center of origin of a wild species (Vavilov, 1930). A similar result was obtained by us with RAPD markers (Liu et al., 2006).

Our results suggest that $P$. domestica was derived from $P$. spinosa because both were closely related. The limitation of our experiment is that only one accession of $P$. spinosa is used, so collecting more accessions of related species and further study on the origin of European plum based on DNA techniques is needed to resolve this question. The evaluation of genetic relationships between European plum-related species is presently under way using cpDNA and mtDNA PCR-RFLP methods in our laboratory.

Classification of stone fruit species - including plum, apricot, cherry, and peach - has long been complicated and problematic due to the diverse phenotypes and large number of species. Some Chinese pomologists still put plum, apricot, cherry, and peach into separate genera, as Prunus L., Armeniaca Mill., Cerasus Mill., and Amygdalus L., respectively (Yu, 1984), and refer to the plum genus as the "small Prunus," but the most widely adopted classification of stone fruit species places all of them under one genus (i.e., Prunus), the so-called "large Prunus" (Lee and Wen, 2001). Our results support the classification of stone fruit species under "large Prunus" because apricot (89), plumcot types (1, 2, 3, 4, 90, 91, 97, and 98), and $P$. tomentosa [named Cerasus tomentosa (Thunb.) Wall. by "small
Prunus" taxonomists] (96) were grouped with the diploid plum species group earlier than European plum (Fig. 2).

\section{Literature Cited}

Ammiraju, J.S.S., B.B. Dholakia, D.K. Santra, H. Singh, M.D. Lagu, S.A. Tamhankar, H.S. Dhaliwal, V.S. Rao, V.S. Gupta, and P.K. Ranjekar. 2001. Identification of inter simple sequence repeat (ISSR) markers associated with seed size in wheat. Theor. Appl. Genet. 102:726-732.

Archak, S., A.B. Gaikwad, D. Gautam, E.V.V.B. Rao, K.R.M. Swamy, and J.L. Karihaloo. 2003. DNA fingerprinting of Indian cashew (Anacardium occidentale L.) varieties using RAPD and ISSR techniques. Euphytica 230:397-404.

Bhutani, V.P. and V.K. Joshi. 1995. Plum, p. 203-241. In: D.K. Salunkhe and S.S. Kadam (eds.). Handbook of fruit science and technology: production, composition, storage, and processing. Marcel Dekker, New York.

Boonprakob, U. and D.H. Byrne. 2001. Genetic relationships among cultivated diploid plums and their progenitors as determined by RAPD markers. J. Amer. Soc. Hort. Sci. 126:451-461.

Byrne, D.H. and T.G. Littleton. 1988. Electrophoretic characterization of diploid plums of the southeastern United States. J. Amer. Soc. Hort. Sci. 113:918-924.

Cekic, C., N.H. Battey, and M.J. Wilkinson. 2001. The potential of ISSR-PCR primer-pair combinations for genetic linkage analysis using the seasonal flowering locus in Fragaria as a model. Theor. Appl. Genet. 103:540-546.

Crane, M.B. and W.J.C. Lawrence. 1952. The genetics of garden plants. Macmillan, London.

Doyle, J.J. and J.L. Doyle. 1990. Isolation of plant DNA from fresh tissue. Focus 12:13-15.

Eryomine, G.V. 1991. New data on the origin of Prunus domestica L. Acta Hort. 283:27-29.

Fang, D.Q., M.L. Roose, R.R. Krueger, and C.T. Federici. 1997. Fingerprinting trifoliate orange germ plasm accessions with isozymes, RFLPs, and inter-simple sequence repeat markers. Theor. Appl. Genet. 95:211-219.

Food and Agriculture Organization of the United Nations. 2006. World production of plums and sloes. 22 Feb. 2007. $<$ http://faostat.fao.org/ site/567/default.aspx $>$.

Faust, M. 1999. Origin and dissemination of plum. Hort. Rev. (Amer. Soc. Hort. Sci.) 23:179-231.

Gilbert, J.E., R.V. Lewis, M.J. Wilkinson, and P.D.S. Caligari. 1999. Developing an appropriate strategy to assess genetic variability in plant germplasm collection. Theor. Appl. Genet. 98:1125-1131.

Goulao, L., L. Monte-Corvo, and O.M. Cristina. 2001. Phenetic characterization of plum cultivars by high multiplex ratio markers: amplified fragment length polymorphisms and inter-simple sequence repeats. J. Amer. Soc. Hort. Sci. 126(1):72-77.

Gupta, M., Y.S. Chyi, J. Romero-Severson, and J.L. Owen. 1994. Amplification of DNA markers from evolutionarily diverse genomes using single primers of simple-sequence repeats. Theor. Appl. Genet. 89:998-1006.

Huang, J.C. and M. Sun. 2000. Genetic diversity and relationships of sweetpotato and its wild relatives in Ipomoea series Batatas (Convolvulaceae) as revealed by inter-simple sequence repeat (ISSR) and restriction analysis of chloroplast DNA. Theor. Appl. Genet. 100:1050-1060.

Jones, C.J., K.J. Edwards, S. Castaglione, M.O. Winfield, F. Sale, C. Van de Wiel, G. Bredemeijer, M. Buiatti, E. Maestri, A. Malcevshi, N. Marmiroli, R. Aert, G. Volckaert, J. Rueda, R. Linacero, A. Vazquez, and A. Karp. 1997. Reproducibility testing of RAPD, AFLP, and SSR markers in plants by a network of European laboratories. Mol. Breed. 3:381-390.

Khush, G.S. 2002. Molecular genetics-plant breeder's perspective, p. 1-8. In: S.M. Jain, D.S. Brar, and B.S. Ahloowalia (eds.). Molecular techniques in crop improvement. Kluwer Academic Publishers, Dordrecht, The Netherlands. 
Lee, S. and J. Wen. 2001. A phylogenetic analysis of Prunus and the Amygdaloideae (Rosaceae) using ITS sequences of nuclear ribosomal DNA. Amer. J. Bot. 88:150-160.

Levi, A. and L.J. Rowland. 1997. Identifying blueberry cultivars and evaluating their genetic relationship using randomly amplified polymorphic DNA (RAPD) and simple sequence repeat-(SSR) anchored primers. J. Amer. Soc. Hort. Sci. 122: 74-78.

Lin, P. and L. Shi. 1990. The discovery and distribution of Ili wild Prunus domestica (P. communis Fritsch) in Xinjiang, p. 282-286. In: Proceedings of International Symposium on Horticultural Germplasm, Cultivated and Wild. Chinese Society for Horticultural Science, Beijing. 5-9 Sept. 1988.

Lin, S.H., F.S. Pu, J.Y. Zhang, X.Y. Gao, and X.J. Li. 1991. Observation on chromosomes numbers of Prunus. China Fruits 2:8-10.

Liu, W.S. 1996. Identification of resistance of Chinese plum germplasm resources to bacterial spot. China Fruits 3:9-11.

Liu, W.S. 2004. Plum production in China. Abstracts of the 8th International Plum and Prune Symposium on Genetics, Breeding and Pomology, Lofthus, Norway, 5-9. Sept. 2004.

Liu, W.S., D.C. Liu, C.J. Feng, A.M. Zhang, and S.H. Li. 2006. Genetic diversity and phylogenetic relationships in plum germplasm resources revealed by RAPD markers. J. Hort. Sci. Biotechnol. 81:242-250.

Luo, X.S., X.S. Chen, Y.K. Guo, and L. Miao. 1992. Studies on the pollen morphology of apricot variety resources. Acta Hort. Sinica 19(4):319-325.

Mantel, N.A. 1967. The detection of disease clustering and a generalized regression approach. Cancer Res. 27:209-220.

Moreno, S., J.P. Martin, and J.M. Ortiz. 1998. Inter-simple sequence repeats PCR for characterization of closed related grapevine germplasm. Euphytica 101:117-125.

Okie, W.R. and J.H. Weinberger. 1996. Plums, p. 559-607. In: J. Janick and J.N. Moore (eds.). Fruit breeding, Vol. 1: Tree and tropical fruits. Wiley, New York.

Qu, Z.Z. and Y.W. Sun. 1990. Comments on fruit species. China Agricultural Press, Beijing.

Ramming, D.W. and V. Cociu. 1990. Plum (Prunus). Acta Hort. 290: 235-287.

Rohlf, F.J. 2000. NTSYS-pc: numerical taxonomy and multivariate analysis system. Exeter Publ., Setauket, NY.
Romesburg, H.C. 1990. Cluster analysis for researchers. Krieger Publ., Malabar, FL.

Ruan, Y., P. Zhou, and C. Liu. 2002. Phylogenetic relationship among nine Prunus species based on random amplified polymorphic DNA. Acta Hort. Sinica 29(3):218-223.

Ryugo, K. 1988. Fruit culture: its science and art. Wiley, New York. Sankar, A.A. and G.A. Moore. 2001. Evaluation of inter-simple sequence repeat analysis for mapping in citrus and extension of the genetic linkage map. Theor. Appl. Genet. 102:206-214.

Shimada, T., H. Hayama, T. Haji, M. Yamaguchi, and M. Yoshida. 1999. Genetic diversity of plums characterized by random amplified polymorphic DNA (RAPD) analysis. Euphytica 109:143-147.

Vavilov, N.I. 1930. Wild progenitors of the fruit trees of Turkistan and the Caucasus and the problem of the origin of fruit trees, p. 271-286. Proc. 9th Intl. Hort. Congr. 7-15 Aug. 1930. Royal Horticultural Society, London.

Virk, P.S., J. Zhu, H.J. Newburg, G.J. Bryan, M.T. Jackson, and B.V. Ford-Lloyd. 2000. Effectiveness of different classes of molecular markers for classifying and revealing variations in rice (Oryza sativa) germplasm. Euphytica 112:275-284.

Wang, Z., J.L. Weber, G. Zhong, and S.D. Tanksley. 1994. Survey of plant short tandem DNA repeats. Theor. Appl. Genet. 88:1-6.

Westwood, M.N. 1993. Temperate-zone pomology: physiology and culture. Timber Press, Portland, OR.

Wu, G.M. 1984. Classification of temperate-zone fruit trees in China. China Agricultural Press, Beijing.

Yoshida, M. 1987. The origin of fruits, 2: Plums. Fruit Jpn. 42:49-53. $\mathrm{Yu}$, D.J. 1984. Classification of deciduous fruit trees. Shanghai Science and Technology Press, Shanghai.

Zhang, J.Y. 1990. Reports on investigation of national plum and apricot germplasm resources. China Fruits 4:29-34.

Zhang, J.Y., W.S. Liu, P.J. Lin, and P. Blanchet. 1998. Preliminary report about wild Prunus domestica L. in Xinjiang (Western China). Acta Hort. 418:347-350.

Zhang, J.Y. and E. Zhou. 1998. China fruit-plant monographs, plum flora. China Forestry Press, Beijing.

Zietkiewicz, E., A. Rajalski, and D. Labuda. 1994. Genome fingerprinting by simple sequence repeat (SSR)-anchored polymerase chain reaction amplification. Genomics 20:176-183.

Zohary, D. 1992. Is the European plum, Prunus domestica L., a $P$. cerasifera Ehrh. $\times P$. spinosa L. allo-polyploid? Euphytica 60:75-77. 